\title{
Enquête
}

Archives de la revue Enquête

5 | 1997

Débats et controverses

\section{Le date rape aux États-Unis}

Figures d'une polémique

Date Rape in the United States. Forms of a Polemic

\section{Éric Fassin}

\section{(2) OpenEdition}

\section{Journals}

Édition électronique

URL : http://journals.openedition.org/enquete/1263

DOI : 10.4000/enquete.1263

ISSN : 1953-809X

Éditeur :

Cercom, Éditions Parenthèses

\section{Édition imprimée}

Date de publication : 1 septembre 1997

Pagination : 193-222

\section{Référence électronique}

Éric Fassin, «Le date rape aux États-Unis », Enquête [En ligne], 5 | 1997, mis en ligne le 15 juillet 2013, consulté le 19 mars 2020. URL : http://journals.openedition.org/enquete/1263 ; DOI : https://doi.org/ 10.4000/enquete. 1263

Ce document a été généré automatiquement le 19 mars 2020. 


\title{
Le date rape aux États-Unis
}

\author{
Figures d'une polémique \\ Date Rape in the United States. Forms of a Polemic
}

\section{Éric Fassin}

1 L'harmonie des sexes, souvent invoquée pour définir la singularité française, ressort toujours par contraste : elle renvoie au négatif d'une autre exception, l'Amérique de la guerre des sexes. Un même geste fonde ensemble, dans l'imaginaire intellectuel français actuel, les deux cultures érotiques, le modèle et le contre-modèle. C'est ainsi par exemple que la réflexion qu'offre Mona Ozouf sur féminisme et féminité reste prisonnière de ce jeu de miroirs. En matière de violence sexuelle, à la juste mesure bien française répondrait le radicalisme américain le plus outrancier : aux États-Unis, selon l'auteur, tout est viol, ou plutôt tenu pour tel. « La conception du viol est emblématique de cet extrémisme. On lui donne aux États-Unis une définition assez élastique pour ne plus comporter l'usage de la force ou de la menace et pour englober toute tentative de séduction, fût-elle réduite à l'insistance verbale. » Séduction en deçà de l'Atlantique, viol au-delà. Dans le domaine de la sexualité, l'égalitarisme américain se paierait donc d'un refus de l'amour, la violence du rapt n'épargnant pas même le consentement au plaisir. En effet, «derrière pareille extension se cache l'idée qu'il n'y a pas de relation sexuelle consensuelle. Même l'acquiescement explicite ne saurait la garantir, si on suppose qu'il a été précédé et préparé par la séculaire, l'insidieuse subordination des femmes ${ }^{1}$ ». Voici les femmes, au nom du féminisme, privées du bonheur de dire « oui » aux hommes, et l'Amérique tout entière définie comme la culture de la guerre des sexes.

2 Le paradoxe, c'est que ce discours emprunte, à usage français, les arguments d'une polémique antiféministe qui fait rage aux États-Unis, au risque de prendre une construction polémique pour la réalité d'une culture. Mona Ozouf procède en effet à une double opération de généralisation, en supposant, d'une part, une culture féministe unifiée et, d'autre part, une totalité homogène, la culture américaine. En outre, elle pose la première au principe de la seconde : « le discours féministe ordinaire » devient la vulgate nationale. Ce culturalisme à double détente bute sur une double difficulté. D'une part, il ignore la controverse qui agite sur ce point le féminisme américain depuis 
une vingtaine d'années : comment définir le viol ? où commence et où s'arrête la liberté de consentir? Tout le débat féministe, loin de s'accorder pour nier le plaisir au nom de la contrainte, porte précisément sur l'articulation de la sexualité et de la violence. D'autre part, il occulte la polémique dirigée, aux États-Unis même, contre le féminisme, et tout particulièrement dans les années quatre-vingt-dix, depuis les attaques contre le « politiquement correct » à la dénonciation du « sexuellement correct ». Bref, on prend un différend qui divise pour une culture commune, une controverse pour un consensus.

\section{Une culture polémique}

3 La polémique contre la culture américaine passe ainsi à côté de la polémique dans la culture américaine. Or, si les sociétés nationales ont en partage ce qu'on peut légitimement appeler des cultures, il est plus commode d'en aborder l'analyse à partir des représentations qui départagent, plutôt que des croyances partagées. Le dissensus est sans doute une meilleure entrée pour l'étude des cultures. C'est du moins ainsi qu'on suggère de lire «l'invite ", proposée par Jean-Claude Passeron, dans sa glose du "fait social total ", «à rechercher dans une société le (ou les) symbolisateurs nodaux qui se distribuent différemment dans les différentes cultures » : ces nœuds sont par définition le point de rencontre des nombreux fils qui tissent une culture, mais en même temps, et pour la même raison, c'est là que se concentrent les tensions les plus fortes ${ }^{2}$.

4 Faire de ces nœuds l'objet de la recherche, c'est repérer, dans des enchevêtrements de significations, qui sont au principe de conflits d'interprétation, le lieu symbolique où se passe, et se joue, quelque chose. C'est se proposer d'appréhender une culture à partir des différends qui la traversent, la déchirent et la rassemblent d'un même mouvement. On voit ainsi se dessiner le renversement de perspective proposé : pour traiter de la violence sexuelle aux États-Unis, il ne s'agit pas d'analyser un point de vue réputé dominant, l'ordre sexuel qui s'imposerait comme une orthodoxie «culturellement correcte ", mais de restituer les termes et l'ensemble des positions d'une discorde qui organise l'espace social. L'objet est alors la construction du rapport entre les sexes comme lieu politique par excellence, aujourd'hui aux États-Unis, à la différence de la France. Ce qui se joue dans cette politisation, c'est moins en effet un affrontement entre les sexes, dernier avatar d'une lutte éternelle, qu'un débat nouveau à propos des sexes, c'est-à-dire de l'articulation entre genre et sexualité.

5 C'est la controverse elle-même qu'il importe d'étudier, avec la double querelle, au sein $\mathrm{du}$ féminisme et autour du féminisme qui, aux États-Unis, constitue le viol en enjeu idéologique national. Plus précisément, il s'agit depuis une quinzaine d'années du viol par un familier (acquaintance rape), voire, plus précisément, de la violence au cœur des jeux de la séduction : quand le viol vient bousculer les figures imposées du rendez-vous amoureux (date), on parle, depuis les années quatre-vingt, de date rape. L'expression se traduit malaisément et son exotisme se prête volontiers à l'ironie. L'incompréhension est double, face au date autant qu'au date rape: d'une part, faute de connaître les règles $\mathrm{du}$ jeu amoureux dans la culture américaine, on en méconnaît les dérèglements ; d'autre part, en ignorant la configuration de la polémique, on s'aveugle à ses enjeux politiques. Bref, on rabat le politique sur la culture, renvoyant la querelle à une " américanité » vague et intemporelle. Il faudrait au contraire en préciser l'inscription au croisement de deux histoires, inséparablement culturelles et politiques - celle d'une 
érotique et celle d'un différend. Délaissant ici la première ${ }^{3}$, nous nous attacherons à la seconde en esquissant, avec l'invention du date rape dans les années quatre-vingt et sa remise en cause dans les années quatre-vingt-dix, la genèse d'une polémique.

\section{L'invention du date rape}

6 Le date rape est une invention féministe des années quatre-vingt. Pourtant, les agressions masculines dans le contexte du date avaient déjà fait l'objet, dans les années cinquante, d'une première découverte, inquiétante, dans les travaux du sociologue Eugène Kanin ${ }^{4}$. Mais ces enquêtes, à la veille de la libération sexuelle, restèrent sans écho et sans suite. Certes, dans les années soixante-dix, le viol devenait un objet politique, avec le développement du féminisme, de Susan Griffin à Diana Russell, en passant par l'ouvrage classique de Susan Brownmiller, Le viol ${ }^{5}$. Mais la lutte contre le patriarcat, si elle poursuivait le viol jusque dans le lit conjugal, ne touchait guère aux charmes de la séduction. Avec l'émancipation sexuelle nouvelle, alors que les règles anciennes du date semblaient vouées aux poubelles de l'histoire érotique, la dénonciation des abus de pouvoir masculins épargnait les jeux de l'amour, ou du moins de la cour amoureuse. La nouveauté des années quatre-vingt, qui caractérise l'invention du date rape, c'est la rencontre des deux discours, scientifique et politique, et des deux problématiques, les dérapages de la séduction s'expliquant par la domination masculine. Le fait nouveau, expliquant la redéfinition des rapports du savant et du politique, c'est l'institutionnalisation du féminisme aux États-Unis, en particulier dans l'université comme dans les médias.

\section{Le féminisme universitaire}

7 Dès 1980, Signs, revue féministe savante, engage un débat sur les statistiques du viol. On savait certes déjà que les déclarations sous-estiment considérablement le phénomène, qu'il s'agisse des plaintes ou des enquêtes officielles : restait à trouver un coefficient de correction fiable. Mais, au-delà de l'établissement des données, la réflexion féministe propose désormais moins de dénombrer l'occurrence annuelle de viols dans la population que de projeter ces chiffres sur l'ensemble d'une vie : pour une femme, quel est à terme le risque de viol? En termes épidémiologiques, l'accent est mis désormais sur la "prévalence » plus que sur l'« incidence». Pour aller plus loin, on se fondera désormais, non plus sur les statistiques du viol, mais sur des enquêtes auprès de femmes : c'est ainsi que Diana Russell estime bientôt à " $26 \%$ le risque qu'une femme soit victime d'un viol abouti à un moment ou à un autre de sa vie », et le taux s'élève à $46 \%$ si l'on inclut les tentatives qui ont échoué. Le viol, loin d'apparaître marginal, devient central : «La violence sexuelle est tellement répandue que la violence contre les femmes se trouve au cœur même de ces interactions entre hommes et femmes que notre culture définit comme "normales"." "

$8 \mathrm{Au}$ même moment, une psychologue de l'université d'État de l'Ohio, Mary Koss, prolonge dans ses enquêtes la logique de l'argument en lui donnant, avec ses échantillons aléatoires, une légitimité scientifique supplémentaire. On retiendra dès lors, le plus souvent, les chiffres qu'elle précise dans l'enquête de 1985, à savoir $15 \%$ de jeunes femmes victimes de viol, auxquelles on peut ajouter $12 \%$, victimes de tentatives - soit un total de plus d'un quart de l'échantillon: «Une sur quatre » ("One in four ») 
devient un slogan mobilisateur sur les campus, au risque de confondre viols et tentatives. Mais la nouveauté radicale, c'est la redéfinition qui donne corps à l'idée d'une « culture du viol ». Elle prend deux formes. D'abord, le viol n'est en réalité que la forme extrême de pratiques ordinaires. Selon Mary Koss, "le viol représente un comportement extrême, sans doute, mais qui s'inscrit dans la continuité des comportements masculins normaux dans la culture. Ce continuum d'agression sexuelle s'étend depuis le rapport obtenu sous contrainte verbale et sous la menace du recours à la force jusqu'au rapport obtenu par l'exercice de la force physique, à savoir le viol ${ }^{7}$ ». Certes, tout n'est pas viol ; mais la différence qui sépare le viol de mainte séduction, moins brutale mais jouant aussi d'un rapport de force, n'est pas de nature mais de degré.

9 Surtout, et c'est le second aspect radicalement novateur, le questionnaire de l'enquête décrit un spectre de situations, dont certaines correspondent à la définition légale et donc externe du viol. Que la femme identifie son expérience comme viol, ou non, il y aurait viol, objectivement, quand le rapport sexuel est imposé à la femme, non seulement contre son gré, mais aussi par la menace ou par la force. L'enjeu apparaît clairement dans les résultats : dans une même enquête, les chiffres sont multipliés par quatre - c'est-à-dire qu'un quart seulement des victimes qualifient leur expérience de viol et près de la moitié n'y voient qu'un problème de communication ${ }^{8}$. Le travail de redéfinition suppose qu'on dépasse les représentations des femmes elles-mêmes, pour reconnaître comme viol ce que, le plus souvent, en dépit de la loi, elles n'appelleraient pas ainsi. L'aboutissement de cette logique en est également la radicalisation - tant dans la réalité décrite que dans la théorie qui en rend compte. L'invention du date rape, c'est bien le résultat d'un effort féministe pour transformer les représentations partagées, implicites, admises, voire revendiquées.

\section{Le féminisme médiatique}

Paradoxalement, la radicalisation de l'argument sur la violence au cœur de la culture hétérosexuelle coïncide avec sa diffusion sociale. C'est que le féminisme médiatique vient relayer le féminisme scientifique. Dès 1982, Gloria Steinem, féministe célèbre, contacte Mary Koss, universitaire de rang modeste, et met la visibilité considérable de son magazine Ms. au service de ses recherches. C'est bien un choix, militant, de publicité, inscrivant la problématique dans le paysage social et non plus seulement scientifique. Les articles sont suivis d'une enquête nationale conduite par Mary Koss auprès de 7000 étudiants sur 35 campus; les résultats en sont publiés en 1988 dans un livre de vulgarisation à succès rédigé par Robin Warshaw ${ }^{9}$. Dans la logique médiatique, l'essentiel est de nommer le phénomène. I Never Called it Rape - jamais on n'avait osé, ou même songé à nommer « cela » viol. C'est bien pourquoi, d'ailleurs, le viol reste occulté. Les femmes craignent effectivement de le déclarer, au sondeur comme au policier. Mais elles ne peuvent, ni même ne savent le nommer: comment penser la violence dans la relation amoureuse?

11 Il s'agit d'abord, pour le féminisme du date rape, d'identifier le violeur. Le viol est fréquent, et il ne représente que la version exacerbée d'un comportement ordinaire. Le violeur n'est donc plus l'exception: le viol se rapproche. Il n'est plus le fait d'un inconnu, malade ou déviant, présumé noir, jaillissant d'un buisson obscur. Bien au contraire, le violeur apparaît maintenant comme un homme «normal », qui même en 
rajoute dans la normalité par son adhésion forcenée à la culture de la masculinité. Il est du même milieu, de même couleur - pire, il est le plus souvent connu, voire populaire comme les garçons des fraternités qui sévissent sur les campus. L'enquête de Ms. le montre : « $84 \%$ des victimes de viol connaissaient leur agresseur ». On retrouve ici la découverte de Kanin dans les années cinquante, que toutes les enquêtes confirment : le viol est massivement perpétré par un familier, dans des circonstances familières - par exemple, dans l'enclos des campus.

Il s'agit ensuite d'identifier le viol. Fréquenté, le violeur est peut-être désiré ou aimé, date d'un soir ou boyfriend d'une saison. Et en effet, selon les étudiantes interrogées par Ms., « $57 \%$ des viols interviennent au cours d'un date». Déjà en 1982, le magazine lançait le date rape dans le titre de son article: le terme est sans doute plus frappant, donc plus efficace (même s'il est plus étroit) que l'original savant acquaintance rape (pour sa part, Koss évoquait le viol « caché »). Mais ce choix publicitaire n'est pas sans conséquence sur la nature du débat qu'il fait porter sur la relation amoureuse. Sans doute, associant le plaisir du date à l'horreur du rape, "l'expression nouvelle est-elle presque impossible à comprendre pour la plupart des gens »; c'est pourquoi tout un travail pédagogique est nécessaire. Il faut dissiper les nombreux mythes qui encombrent la culture érotique : traditionnellement, il n'y aurait pas viol si la femme accepte d'entrer dans la maison ou la voiture de son compagnon, s'il a payé pour le dîner ou la sortie, si elle a déjà accepté ses baisers ou ses caresses ; la femme perdrait alors le droit de dire non à l'homme. Ce que proposent les féministes du date rape, c'est d'écarter le soupçon pesant sur la femme qui se risque à crier au viol, trop souvent présumée coupable ("elle l'avait bien cherché ») ou mensongère ("que va-t-elle chercher là ?»). Bref, le féminisme, pour accorder du crédit au point de vue des femmes, entreprend de redéfinir ce crime.

\section{Les ambiguiités du succès}

Le succès social de la notion de date rape est remarquable. Grâce aux médias, le terme entre aisément dans l'usage, des émissions télévisées populaires aux magazines à grande diffusion. À l'université, ce ne sont pas seulement la recherche et l'enseignement : se mettent en place en même temps, côté étudiants, les permanences téléphoniques de volontaires et les célèbres marches (Take Back the Night), et, côté administration, des services de lutte contre le viol, avec des règlements intérieurs nouveaux et des structures d'accueil pour les victimes, sans oublier les lumières bleues qui ponctuent la nuit des campus. Les universités répondent ainsi à la demande d'étudiantes, féministes ou non, et plus encore à la pression conjuguée des parents et des autorités qui, dès 1992, subordonnent leurs subventions à de telles mesures. Car le plus frappant est sans doute le succès de la campagne auprès de la bureaucratie fédérale, qui modifie la même année les procédures d'enquêtes sur le viol dans le National Crime Survey, entraînant une révision à la hausse des estimations, et bientôt du Congrès, puisque le Violence Against Women Act qu'introduit le sénateur Joseph Biden en 1993 consacre une section (Title IV), et un budget important, à la lutte contre le viol sur les campus.

Quelques procès particulièrement médiatisés sont pour beaucoup dans cette reconnaissance publique. Fin 1991, William Smith, un rejeton de la dynastie Kennedy, est en procès pour viol, en même temps que le champion du monde de boxe, Mike 
Tyson : le premier est acquitté, le second est condamné à six ans de prison. Ces deux affaires médiatico-juridiques, qui opposent chacune deux versions inconciliables du même événement, sont d'autant plus importantes que leur vertu pédagogique vient renforcer les leçons de l'automne 1991 : début octobre, le juge Clarence Thomas était accusé de harcèlement sexuel par une ancienne collaboratrice, Anita Hill. L'extraordinaire retentissement des auditions devant le Sénat, et les caméras, fait entrer dans le langage commun et la conscience publique, plus qu'un vocabulaire (pour l'expression sexual harassment, la chronologie de la diffusion correspond à peu près à celle du terme date rape), une problématique : les rapports de pouvoir se jouent aussi, bien souvent, sur le terrain des relations sexuelles. La leçon des procès pour date rape vient donc compléter, symétriquement, la logique de cette problématique : les relations sexuelles n'en sont pas moins des rapports de pouvoir. Dans un cas comme dans l'autre, l'ordre sexuel est un ordre politique.

Ces grandes affaires viennent ainsi parachever dix années de construction sociale de la violence sexuelle, et singulièrement du date rape. La pédagogie du fait divers consacre la reconnaissance de cette notion, les noms de Tyson et de Kennedy prêtant leur résonance symbolique à la cause, tout comme d'autres affaires, impliquant par exemple le cinéaste Woody Allen ou le chanteur Michael Jackson, viendront bientôt enrichir la mise en scène nationale d'une réflexion sur la violence sexuelle. Mais il ne s'agit pas seulement de personnalités : dans leur sillage, les frères Menendez ou les époux Bobbitt ne deviendront pas moins célèbres. Simplement, les procès à grand spectacle ne font que rendre visible ce qui restait caché jusqu'alors. Les stars n'apparaissent donc pas dans une logique d'exception, mais d'illustration ou plutôt de révélation d'un phénomène national.

16 Faut-il voir pour autant dans ce moment le triomphe ultime de la notion de date rape? L'hégémonie féministe aurait-elle réussi à redéfinir la culture américaine ? En fait, la publicité nationale de ces procès, au lendemain de l'affaire Thomas, marque moins la domination d'une problématique qu'elle n'en révèle les ambiguïtés. Loin d'exprimer un consensus, la dramaturgie du procès offre le spectacle d'un différend social, et sexuel. Il est vrai que les féministes du date rape sont parvenues à poser, au niveau national, la question de la violence sexuelle; il serait pourtant trompeur de croire qu'elles ont réussi à en imposer la réponse. L'ambiguïté est en effet constitutive du débat, les affaires l'ont bien montré : comme pour le harcèlement sexuel, avec le date rape, nous entrons dans un double jeu d'interprétations.

D'une part en effet, dans la grande majorité des cas, c'est la parole d'une femme contre la parole d'un homme: "dit-il», "dit-elle», voilà la rengaine des procès - non seulement faute de preuves ou de témoins, mais parce qu'il s'agit moins d'opposer mensonge et vérité que de reconstituer deux vérités, ou plutôt deux interprétations. Dans l'histoire de Rashomon, la multiplicité des points de vue cachait, puis révélait une vérité. Ici, en revanche, l'un et l'autre peuvent être d'une égale bonne foi, chacun recelant sa vérité. Les récits féminins de date rape sont d'autant plus pathétiques que, pour leur agresseur, il ne s'est réellement rien passé - ou plutôt, quand tout s'est bien passé. D'autre part, on l'a vu, le date rape résulte bien d'une construction féministe : la réalité est donc difficilement séparable de sa nomination. En lui donnant un nom, le féminisme a fait advenir une réalité nouvelle, au terme d'un véritable travail d'invention. C'est bien pourquoi les victimes elles-mêmes ne pouvaient identifier leur propre expérience avant qu'un langage nouveau n'en reconnaisse l'existence. Le date 
rape, ce n'est donc pas simplement le point de vue des femmes, contre celui des hommes, mais aussi l'interprétation qu'en propose le féminisme. Ce double niveau d'interprétation, qui fait toute l'ambiguïté du date rape, définit un double conflit d'interprétations. C'est dans cet espace que s'engouffre, au moment où la logique du date rape semblait devoir l'emporter, la polémique contre ce concept.

\section{La polémique contre le date rape}

Jamais le date rape n'a fait l'unanimité aux États-Unis. Loin de s'imposer comme une évidence, la notion s'est toujours définie contre le sens commun, non seulement masculin mais aussi féminin. Le fait nouveau, au début des années quatre-vingt-dix, c'est que l'opposition s'organise et engage une contre-attaque idéologique. Pour apprécier son efficacité, il suffit de considérer l'évolution du magazine Time, entre 1987 et 1991 - de la forme affirmative à la forme interrogative. Le premier article présente le date rape comme une réalité, et la prise de conscience sociale comme un progrès : "Les temps sont peut-être en train de changer.» Le dossier de couverture, quatre ans plus tard, met l'accent sur une incertitude, et un débat : «Quand y a-t-il viol ? " Comment départager l'accusatrice et l'accusé, « quel juge omniscient décidera s'il y avait bien un consentement mutuel authentique ${ }^{10}$ ? " L'incertitude laisse bientôt la place au soupçon : à l'automne 1993, Newsweek fait sa couverture en lançant l'expression «sexual correctness » : «Est-on allé trop loin ? » La réponse est clairement suggérée : «Attention à ce que vous dites, attention à ce que vous faites. Les règles nouvelles de la politique féministe vont-elles libérer les femmes, ou les ramener en arrière ${ }^{11}$ ? " L'interrogation cache mal une forme négative. Et la polémique sur le "sexuellement correct » vient relayer la bataille du "politiquement correct», dont le potentiel médiatique semble épuisé après trois années ${ }^{12}$.

\section{Les deux fronts de la contre-attaque}

Comment expliquer ce tournant? Il marque le succès polémique d'une contre-attaque qui s'ouvre simultanément sur deux fronts. Les intellectuels conservateurs, et les magazines masculins, n'avaient bien entendu jamais accepté le discours nouveau. La réaction n'intervient pourtant qu'au tournant des années quatre-vingt-dix, avec une série d'articles. C'est en particulier l'attaque de Neil Gilbert, professeur de politiques sociales à Berkeley, dans The Public Interest: démontant les enquêtes féministes, les chiffres et les définitions, il parle d'une "épidémie fantôme ». Les féministes gonfleraient les statistiques hors de proportion, dans un rapport de 1 à 500 (il est vrai aussi qu'on repasse avec lui de la prévalence à l'incidence...). C'est que, pour elles, tout serait viol - bien au-delà des définitions légales : c'est ainsi que les cas d'incapacité à consentir, par abus d'alcool ou de drogues, sont comptabilisés avec les viols, gonflant indûment les chiffres. Le viol s'étend bien au-delà même des perceptions des actrices, sans parler des acteurs : sont comprises des situations que ni l'homme, ni la femme ne qualifieraient de viol.

Les adversaires de Neil Gilbert ne manquent certes pas de dénoncer son incompétence : jamais il n'a conduit la moindre recherche sur le viol. Il n'empêche, il parle non seulement au nom du bon sens, mais aussi avec l'autorité du savant. Il importe dans le débat idéologique la rhétorique d'une contre-expertise scientifique. Aussi tous les 
auteurs le citeront-ils désormais pour dénoncer l'importance accordée au date rape et saper la fragile et récente légitimité scientifique de la construction féministe. Mais il s'agit clairement d'une bataille idéologique. C'est pourquoi, en second lieu, Norman Podhoretz, intellectuel (néo-)conservateur de renom, reprend dans Commentary l'offensive contre "le viol d'un point de vue féministe», en développant ses implications sociales : c'en est fini de la séduction. "Les malheureux jeunes gens, garçons ou filles, trop impressionnables, trop faibles ou apeurés pour résister aux contraintes du nouvel ordre sexuel, devront à ses auteurs féministes une vie de solitude, de frustration, de ressentiment et de stérilité.» Les responsables sont clairement désignées, avec «l'influence dans le mouvement des lesbiennes ${ }^{13}$ ».

En cette même année, un deuxième front s'ouvre dans les médias, à commencer par les journaux populaires : c'est dans New York Newsday que la nouvelle star médiatique post(ou anti) féministe, Camille Paglia, lance sa diatribe contre le féminisme du date rape: "Abandonner le sexe aux féministes, c'est confier son chien, pour les vacances, à l'empailleur. » L'attaque trouve un écho dans un organe plus légitime: Katie Roiphe publie dans le New York Times le point de vue d'une jeune étudiante exaspérée par "l'hystérie féministe", bientôt repris par Play-boy (où Camille Paglia est aussi interviewée). La jeune inconnue y gagne la célébrité et le contrat d'un livre - dont le magazine du New York Times, lui consacrant sa couverture en 1993, assurera d'ailleurs le succès : avec une ironie involontaire, elle s'en prend à l'engouement médiatique qui, avec le date rape, consacrerait un mouvement qui «trahit le féminisme ${ }^{14}$ ». Sans doute, d'un auteur à l'autre, le point de vue n'est-il pas identique. Pour Camille Paglia, la femme doit choisir avec prudence « où elle va, et avec qui »: « une fille qui se laisse enivrer au cours d'une soirée organisée par une fraternité est une imbécile ». Pour Katie Roiphe, en revanche, l'excès de prudence nous vient du féminisme du date rape : ses appels à la vigilance, contre l'abus d'alcool et de drogue qui « empêchent de penser clairement et de communiquer efficacement", rappellent trop à son goût la tempérance victorienne. Celle-ci reproche donc au féminisme d'être trop timoré, cellelà trop inconscient. Mais dans un cas comme dans l'autre, les auteurs sont des femmes qui, loin de se réclamer du conservatisme, revendiquent l'héritage d'émancipation des années soixante - souvenirs de jeunesse pour la première, filiation par la mère pour la seconde. Elles parlent au nom des femmes, et pour la libération sexuelle. Leur dénonciation du féminisme se donne par conséquent comme une restauration du féminisme : on retrouvera cette rhétorique chez d'autres auteurs.

\section{Idéologie et rhétoriques de l'anti-féminisme}

Les attaques post-féministes se confondent-elles avec les diatribes conservatrices ? À certains égards, leurs arguments se recoupent bien. Pour Camille Paglia, le viol est inscrit dans la nature. En effet, «il y a des choses qu'on ne peut changer. Il y a des différences sexuelles qui sont fondées dans la biologie ». D'où sa querelle contre les féministes : "Le féminisme universitaire est perdu dans un brouillard où tout est construction sociale. » Or, si la sexualité est une affaire de nature, « il n'y a jamais eu, et il n'y aura jamais d'harmonie sexuelle». Bref, "sexuellement, les femmes seront toujours en danger ». Et qui plus est, c'est une bonne chose : le féminisme "manque entièrement le désir sanguinaire du viol, la joie de la violation, et de la destruction ${ }^{15}$ " Ce qu'on ne peut changer, c'est donc en fait ce qu'on ne doit pas changer : la fin du viol marquerait la mort du désir. Norman Podhoretz ne dit pas autre chose: "Un 
adolescent est d'ordinaire une créature en état de perpétuelle anxiété sexuelle. La vue de n'importe quelle fille, n'importe où, n'importe quand, peut le plonger dans une fièvre libidineuse. Ce qui aggrave la furie de son état, c'est l'injustice des choses. » En effet, par contraste, "il est de toute évidence aussi facile [pour la jeune fille] qu'impossible pour lui de dire "non" au sexe». Tout s'explique à la fois : si «le désir sexuel masculin, dans son agitation continuelle, [paraît] si étrange et effrayant pour tant de femmes, jeunes ou moins jeunes", c'est qu'elles sont "gouvernées par des pulsions érotiques bien plus paisibles ». Comme pour Paglia, changer cette nature, ce serait tuer le désir. Cette logique fondamentalement conservatrice, qui renvoie la sexualité à la nature, se retrouve chez Katie Roiphe ou Neil Gilbert. Mais la belle unanimité laisse apparaître aussi une profonde divergence entre les discours conservateur et post-féministe.

Pour Neil Gilbert en effet, avec le date rape, le féminisme veut donner le pouvoir sexuel aux femmes : «La prescription féministe redéfinit la moralité conventionnelle afin de donner aux femmes le contrôle complet de l'intimité physique entre les sexes. » Pour Katie Roiphe en revanche, le coup de force se renverse en aveu de faiblesse: le féminisme «renforce les stéréotypes traditionnels sur la fragilité du corps et de la volonté des femmes». La femme doit cesser d'être passive, pour s'affirmer sexuellement. Bref, pour les conservateurs, le féminisme est coupable d'arracher les femmes au victorianisme, et pour les post-féministes, de les y enfermer ${ }^{16}$. Les premiers mettent donc l'accent sur une prise de contrôle féminine qui, selon Norman Podhoretz, transforme les hommes en «lavettes» («wimps») : c'est renverser la hiérarchie naturelle des genres. Les secondes insistent sur l'indépendance, la responsabilité et la force caractéristiques des femmes: pour Camille Paglia, «il est indigne d'une forte femme d'aller se plaindre auprès de Papa et Maman » (en l'occurrence, l'administration universitaire). Une bonne gifle ferait l'affaire ${ }^{17}$. Les post-féministes s'élèvent donc contre le culte de la victimisation qui définirait aujourd'hui le féminisme, réduisant les femmes en "femmelettes» du temps passé ("shrinking violets») : c'est revenir à la traditionnelle hiérarchie des genres.

La polémique antiféministe s'appuie donc sur deux rhétoriques contradictoires. Mais, loin de l'affaiblir, ce dédoublement la renforce: comme Janus, l'anti-féminisme présente deux visages, qui peuvent séduire deux publics. L'efficacité de la polémique vient en effet de ce que la dénonciation du féminisme ne touche pas seulement un public conservateur, a priori acquis. Sans doute l'autorité scientifique, médiatiquement déployée, y est-elle pour quelque chose: Neil Gilbert transporte dans les colonnes du Wall Street Journal et les studios de télévision sa légitimité professorale. Mais il y a plus. La polémique séduit un autre public avec les arguments post-féministes, jusque dans les rangs libéraux et même féministes. Pour convaincre un public "progressiste", on recourt volontiers à des arguments « de gauche ». Voici les post-féministes soucieuses de hiérarchie et de classes sociales: elles s'en prennent en effet à un féminisme d'enfants gâtées, l'enseignante Paglia et l'étudiante Roiphe s'accordant pour stigmatiser les privilégiées des campus. De même, Christina Hoff Sommers s'indigne de l'iniquité du féminisme bourgeois. Les femmes pauvres seraient plus exposées à la violence sexuelle; et pourtant, "l'attention et les fonds sont dirigés, de manière disproportionnée, vers celles qui courent le moins de risques ${ }^{18}$ ».

La rhétorique de classe, utilisée comme une arme contre le féminisme, rappelle étrangement certaines attaques beaucoup plus à gauche : à propos du date rape, le 
magazine Women and Revolution, revue de la Commission des femmes de la Ligue spartakiste, s'en prend aussi à "l'hystérie féministe ", véritable écran de fumée qui empêche de voir la "vraie violence » dirigée contre les femmes dans un système de classes $^{19}$. Aux "progressistes ", le post-féminisme peut d'ailleurs emprunter, sur le modèle de la classe, un autre argument, multiculturaliste cette fois : pour Katie Roiphe, si le date rape est bien un problème de mauvaise communication, c'est le résultat de la politique de diversité qui enrichit les campus. Avec « l'introduction d'étudiants noirs, asiatiques, juifs» et la "juxtaposition de cultures différentes", mais aussi avec la "démocratie » nouvelle, qui fait sortir "la riche héritière sudiste" avec «le fils de plombier du Bronx ", bref, avec l'hétérogénéité culturelle et sociale, la communication n'est plus transparente. «L'impulsion conservatrice du mouvement contre le date rape, en conclut Katie Roiphe, c'est que les femmes doivent être protégées des hommes qui ne viennent pas du même milieu ${ }^{20}$. » Nulle donnée ne vient corroborer cette hypothèse. Et de fait, on l'a vu, pour le féminisme du date rape, socialement, le violeur n'est pas l'autre mais le même. Il n'empêche: seule compte l'efficacité rhétorique parmi des lecteurs « progressistes » que les arguments conservateurs ne sauraient atteindre.

\section{L'efficacité polémique}

De manière générale, à l'inverse des conservateurs qui revendiquent un ordre sexuel traditionnel, Camille Paglia ou Katie Roiphe renvoient leur adversaire féministe dans l'archaïsme. Qu'il s'agisse du genre ou de la sexualité, elles se veulent «modernes », en revendiquant l'héritage d'émancipation féminine et de libération sexuelle des années soixante, bref, d'un féminisme plus souriant. Pour mesurer l'efficacité de cette construction, il suffit d'en vérifier l'impact sur une figure de proue du féminisme médiatique. L'essayiste Naomi Wolf se lance en 1991 avec un best-seller, The Beauty Myth, où elle dénonce les ravages d'une industrie, et surtout d'une idéologie de la beauté qui maintient les femmes captives d'une cage dorée. L'argument résonne avec celui de la journaliste Susan Faludi sur le « retour de manivelle » ("backlash») dont les femmes auraient été victimes dans les années quatre-vingt. On s'entiche alors, dans les médias, de la nouvelle génération féministe. Mais le succès est de courte durée : à trop dénoncer la domination, ces féministes n'enfermeraient-elles pas les femmes dans la victimisation? C'est l'argument des post-féministes, qui s'imposent presque simultanément sur la scène médiatique. Les jeunes féministes, vedettes d'un soir, ont beau protester : le mal est fait. Ainsi, Naomi Wolf est toujours citée dans la polémique pour sa reprise sans nuance de l'idée d'une « culture du viol». La voici donc contrainte de corriger son image: en réponse à l'ironie de Camille Paglia, elle s'affiche "prosexe », jusqu'à raconter son premier orgasme dans les colonnes de la New Republic. Dans le même temps, contre l'accusation de Katie Roiphe, elle se réclame d'un «féminisme de la puissance ", jusqu'à consacrer tout un livre à répudier le "féminisme de la victimisation » - quitte à prendre ses distances avec les « excès » du féminisme du date rape, sans renier pour autant la notion ${ }^{21}$.

Qu'on insiste sur l'unité idéologique ou sur la dualité rhétorique des attaques conservatrices et post-féministes, l'essentiel est dans leur cohérence polémique. En effet, pour tous ces auteurs, le date rape est moins une vérité révélée que dévoyée, moins une « invention » du féminisme qu'une dangereuse «fabrication ». La cohérence entre les deux fronts se manifeste donc tout simplement dans leur convergence contre un ennemi commun, révélée par le recours systématique à une même phrase: en 
matière de sexualité féminine, « considérer le "oui" comme le signe d'un consentement véritable, c'est faire fausse route ». La citation, empruntée à la juriste libérale Susan Estrich, est tronquée au point d'inverser son propos, puisque celle-ci définissait justement son analyse par opposition à ce point de vue. Bref, on ne lit plus la juriste qu'avec les lunettes de ses critiques.

La circulation du contresens est symptomatique d'une volonté polémique commune de réduire la diversité des points de vue féministes sur le date rape à une seule position, la plus extrême, et la plus vulnérable, qui voit le viol partout: même la femme consentante serait une victime. L'erreur a son utilité polémique, puisqu'elle enferme l'adversaire dans une position indéfendable. Parler de date rape, reviendrait à condamner l'hétérosexualité dans son entier. Le féminisme ne serait donc que la théorie d'une pratique, le lesbianisme. On le conçoit aisément: cette reductio ad absurdum permet ensuite, au nom de la possibilité d'un bonheur hétérosexuel, de récuser le féminisme dans son entier.

\section{Les figures du consentement}

29 Si nous voulons échapper aux réductions polémiques, et déployer l'ensemble des positions dans la polémique, y compris celle de Susan Estrich, il faut revenir sur la question du consentement, qui renvoie aux représentations de la sexualité féminine. En effet, le consentement masculin est supposé acquis d'avance - soit qu'on accorde à l'homme le privilège d'un désir toujours prêt, soit qu'on lui concède l'avantage systématique de l'initiative. Chez l'homme, le «oui» ne serait donc jamais problématique, ni ambigu ni incertain - soit par un effet de sa nature, soit en raison de sa culture ${ }^{22}$. Précisons encore : la question du consentement ne se pose ou plutôt n'est posée qu'en termes d'hétérosexualité. C'est que la différence supposée de nature (ou de culture) sexuelle entre les sexes a précisément pour fonction de penser le rapport entre hommes et femmes. Pour quiconque s'aventure à parler du viol hétérosexuel, c'est bien le consentement féminin qui est en question.

\section{Quand « non », c'est « oui » : l'érotique conservatrice}

30 La première figure du consentement se rencontre chez les conservateurs. Pour eux, la femme semble souvent se refuser, alors que son désir acquiesce. C'est d'ailleurs, selon Norman Podhoretz, ce qui fait le charme de la conquête. De la froideur extérieure des jeunes filles, et de la chaleur intérieure qui le consume, l'adolescent « retire très tôt la leçon que son seul espoir de briser cette incompréhensible indifférence est de ne jamais, à aucune étape de la séduction, s'arrêter à un refus - et c'est là, il l'apprend aussi précocement, ce que certaines, sans doute la plupart, attendent de lui ». La femme désirée se rend plus désirable encore en se dérobant au désir : "playing hard to get ", c'est à la fois protester qu'on n'est pas une fille facile, et jouer de son esquive afin d'accroître son pouvoir de séduction. La séduction, c'est donc l'art de transformer, fûtce par la force, pour l'homme, et la manipulation, pour la femme, un "non» en un « oui » - tel Rhett Butler s'emparant de Scarlett O'Hara, dans le Sud traditionnel d' Autant en emporte le vent, pour la conduire en dépit de ses protestations, mais non contre son gré, vers les délices du lit. 
31 L'érotique conservatrice du rapt a pour elle la sagesse des nations. Les enquêtes semblent d'ailleurs donner raison à ceux qui protestent contre les rigueurs du féminisme du date rape. De fait, il n'est pas rare que la femme oppose un refus symbolique, et une résistance pour la forme, afin de mieux signifier son assentiment les intéressées en conviennent elles-mêmes volontiers. Sur un campus d'Alabama, parmi les jeunes femmes interviewées, un peu plus d'un tiers seulement ne pratiquent jamais ce double jeu, et autant y recourent souvent, voire toujours ${ }^{23}$. Dans le Texas, $40 \%$ emploient parfois le «non » (et pour la très grande majorité, récemment), quand c'est « oui » qu'elles veulent dire - pour des raisons mêlées, il est vrai, où le jeu érotique n'entre pas pour une plus grande part que la gêne, ou la prudence. De telles recherches, qui alimentent le scepticisme conservateur, ne laissent pas d'embarrasser les féministes qui les entreprennent : les voici condamnées à rappeler que, « si c'est bien "non" que la femme veut dire, et que l'homme s'entête, il y a viol»; or, "quand une femme dit "non", il y a des chances pour qu'elle veuille dire "non" 24 ". La position de Robin Warshaw n'est pas plus facile quand, dans son manuel de lutte contre le date rape, elle appelle les hommes à prendre un «non " pour un « non » : "Si une femme dit "non", et en réalité veut dire "oui, mais il faudra me convaincre", alors, de toute façon, elle ne doit pas vous intéresser. Elle joue un jeu, un jeu où personne ne gagne. Oubliez cette “occasion ratée”. Laissez tomber. » À quoi le conservateur Norman Podhoretz, avec une familiarité ironique, peut facilement répondre: "Tu parles» («Fat chance») ${ }^{25}$. Le féminisme du date rape serait-il voué au silence par les ambiguités ou les contradictions de l'érotique féminine, legs de l'époque victorienne?

\section{Quand « oui », c'est « non »: le féminisme culturel}

Nullement. La première réponse au problème posé par les conservateurs est proposée par les féministes dites «culturelles». Contre les féministes radicales, pour qui la politisation de la sexualité suppose d'en penser à la fois « le plaisir et le danger ${ }^{26}$ ", les féministes culturelles, opposant la culture des femmes à la culture dominante, font porter leur réflexion sur la seule violence - de la pornographie au harcèlement sexuel, en passant par le date rape. Au terme d'un véritable Yalta féministe, au début des années quatre-vingt, tandis que les radicales appliquent leurs analyses au seul lesbianisme, les féministes culturelles se concentrent exclusivement sur l'hétérosexualité.

Pourquoi la femme dit-elle parfois «non », quand elle voudrait dire « oui »? Selon Andrea Dworkin ou Catharine MacKinnon, figures emblématiques du féminisme culturel, pour la même raison que son « oui » peut signifier un " non ». Nous sommes loin de la jeune fille modeste, prude ou coquette, invoquée par les conservateurs : c'est que la domination masculine prive les femmes de la liberté de consentir. Parce que l'inégalité des sexes l'empêche de rester maîtresse de son désir, la femme n'est véritablement libre ni de se donner, ni de se refuser. C'est bien ainsi, comme l'envers et l'endroit d'une même logique, qu'il faut comprendre cet argument sur le viol. Si pour le féminisme culturel le rapport sexuel doit être compris comme un viol, si l'homme devient avec la pénétration comme une armée d'occupation, la femme entre par là même dans une logique politique de collaboration. Pour Andrea Dworkin, la femme n'est plus la complice d'un jeu, mais la collaboratrice d'une invasion ${ }^{27}$. La femme dit « oui » à l'homme, ou bien "non », sans jamais rien dire que sa domination : sa parole 
sexuelle ne lui appartient pas en propre. Voici l'érotisme, non pas annulé, mais traversé par la domination : l'homme jouit de dominer, la femme d'être dominée.

Ainsi, pour le féminisme culturel, l'inégalité de genre traverse, de part en part, la sexualité. Selon Catharine MacKinnon, "pour les femmes, dans des conditions de domination masculine, il est difficile de distinguer le viol du coït ». L'affirmation d'un lien nécessaire entre le rapport sexuel et la domination, c'est le brouillage des limites. Il ne s'agit plus de rabattre le viol sur la violence, comme le proposait dans les années soixante-dix la féministe radicale Susan Brownmiller, mais de faire entrer le viol dans notre compréhension de la sexualité : ce n'est pas la violence qui définit le viol, mais la domination. "La question est moins de savoir s'il y a usage de la force ", poursuit Catharine MacKinnon, « que si le consentement est un concept qui a du sens ». Car «le consentement est une communication sous condition d'inégalité. Il se situe quelque part entre ce que la femme voulait réellement, ce qu'elle a pu exprimer de ce qu'elle voulait, et ce que l'homme a compris de ce qu'elle voulait ${ }^{28} »$. On conçoit que dans ces conditions la juriste ait dû se défendre de l'accusation d'être "anti-sexe». Il faut pourtant voir la logique de son analyse. Ce n'est pas, comme le prétendent ses adversaires, que tout est viol; mais plutôt que, dans un rapport dominé, le consentement n'est qu'une illusion.

\section{Quand « non », c'est « non » : le féminisme libéral}

Les féministes libérales proposent une réponse alternative au problème soulevé par les conservateurs. Loin de mettre en doute la transparence de la parole féminine, elles s'en font les championnes : pour elles, "non », c'est «non». Non pas, bien sûr, qu'elles s'aveuglent sur l'ambiguïté des comportements. Mais c'est ici qu'on comprend le fossé qui sépare Catharine MacKinnon de Susan Estrich, dont le libéralisme juridique se définit par contraste avec le féminisme culturel. Que dit la loi ? La résistance de la femme violée n'est plus aujourd'hui légalement requise pour définir le viol, du moins en théorie. Mais il ne suffit pas pour autant de prouver que la victime a refusé son consentement, ni même que l'agresseur a pu avoir recours à la force, ou à la menace. Dans les cas de date rape, en particulier, la loi pose la question de savoir s'il était raisonnable pour l'accusé de croire que la plaignante consentait. Cette «croyance raisonnable au consentement » devient bien sûr problématique dès lors que le " non » de la femme peut raisonnablement être interprété, parfois ou souvent, comme un « oui ». Féministes culturelles et libérales proposent ici deux solutions, c'est-à-dire deux infléchissements du droit diamétralement opposés.

Pour Catharine MacKinnon, le seul moyen de contrecarrer dans la loi la domination masculine, c'est de refuser l'objectivité pour affirmer «le point de vue des femmes». Aussi ne veut-elle pas retenir la signification de l'acte pour l'agresseur, mais la perception de la victime. «Le problème en profondeur est que la loi suppose en matière de viol l'existence d'une situation unique, objective, qu'il convient simplement de déterminer avec des éléments de preuve, alors qu'en fait tant de viols impliquent des hommes honnêtes et des femmes violées. Lorsque la réalité est coupée en deux, seraitce que la femme est violée, mais non par un violeur ${ }^{29}$ ? » Pour le féminisme culturel, la loi doit donc se fonder sur la perception du viol chez la victime.

Tout au contraire, la juriste libérale Susan Estrich veut sauvegarder le principe légal, et donc le réformer. Elle conjure ainsi le péril subjectiviste que le féminisme culturel fait 
courir au droit. La solution est simple : si l'on veut conserver l'idée d'une «croyance raisonnable au consentement ", il convient de lui conférer plus d'objectivité. Il faut et il suffit qu'au regard de la loi, le refus soit sans équivoque: "non», c'est «non». L'homme raisonnable devient alors celui qui l'entend ainsi. Sans doute n'est-ce pas (encore) vrai dans la société. Susan Estrich reconnait volontiers que «le droit n'a pas inventé la philosophie du "non veut dire oui", même s'il lui a donné force de loi depuis bien longtemps ». Inversement, si le «non » peut cacher un « oui », et nous retrouvons ici une citation trop (mal) connue, «bien des féministes diraient que, aussi longtemps que les femmes sont impuissantes face aux hommes, considérer le "oui" comme le signe d'un consentement véritable, c'est faire fausse route. Pour ma part, je suis bien certaine que beaucoup de femmes qui disent "oui” à des hommes qu'elles connaissent, lors de dates ou bien au travail, diraient "non" si elles le pouvaient. Je ne doute aucunement que le silence des femmes soit parfois le produit, non de la passion et du désir, mais de la pression et de la peur. Pourtant, si "oui" peut souvent vouloir dire "non", du moins d'un point de vue féminin, ce n'est pas trop demander, me semble-t-il, aux hommes et à la loi, que de respecter le courage de la femme qui dit "non", et de la prendre au mot ".

À la femme qui ne peut pas dire "non", la juriste libérale n'a donc rien à offrir. À la femme qui n'ose dire «oui», non plus. Par contraste avec le féminisme culturel, le féminisme libéral pose de fait l'hypothèse d'une femme libre de consentir, ou plutôt, on verra l'importance de cette distinction, de refuser son consentement. Quant à l'homme, il apprendra vite sa leçon : il en ira du viol, suggère Susan Estrich, comme du duel, prohibé par les tribunaux anglais au tournant du xixe siècle. "Il pourrait bien ne pas être nécessaire de poursuivre trop de "messieurs de qualité" avant qu'il ne soit généralement entendu que l'honneur masculin n'est pas incompatible avec l'autonomie féminine. "Sans doute le droit, loin de seulement l'enregistrer, redéfinit-il alors la norme sociale. Mais il faut choisir: «La loi peut soit nous enchaîner au passé soit contribuer à nous pousser vers l'avenir ${ }^{30}$. »

\section{Entre deux logiques, la pratique}

On le voit, la différence entre les deux féminismes n'est pas simplement une variation de degré mais une opposition entre deux logiques : le premier suppose une femme libre de refuser son consentement, tandis que pour le second elle est définie par la domination, jusque dans sa sexualité. Le féminisme du date rape oscille pourtant entre les deux versions. La question de la transparence du sujet féminin, essentielle dans l'argument libéral, est par exemple clairement posée lors d'un procès retentissant. C'est l'affaire de Glen Ridge, dans une banlieue aisée du New Jersey. En 1992, quatre jeunes hommes sont condamnés pour des faits qui remontent à 1989 : un groupe d'adolescents avait abusé d'une jeune fille, dans un sous-sol - jouant même d'un manche à balai, et d'une batte de baseball. Elle était consentante, assurent leurs avocats au procès. Comment pouvait-elle l'être, répond l'accusation? Cette adolescente de 17 ans avait en effet un âge mental de 8 ans. Elle n'était pas en possession des facultés lui permettant d'exercer son jugement : elle ne pouvait consentir librement à ce rôle. Il y aura donc, pour le jury, viol collectif. L'exception sert ici à confirmer la règle : l'enfant, qui ne sait dire que "oui», est l'envers de la femme, qui a le pouvoir de dire "non». Une définition justifie l'autre. Ce n'est donc pas «la » femme, mais certaines, pas encore femmes, qu'on déclare inaptes à consentir : nous restons bien dans la logique libérale. 
40 Le problème est que l'exception peut devenir la règle, et c'est alors qu'on voit le féminisme du date rape hésiter entre les deux logiques, voire basculer dans la logique du féminisme culturel. L'incapacité à consentir peut en effet concerner non plus quelques femmes, mais la plupart, dès lors qu'elles sont sous l'empire de l'alcool, ou d'une drogue. La question n'est pas théorique : dans l'enquête de Mary Koss, pour la majorité des victimes, un excès ou l'autre précède le viol. L'hypothèse d'un lien entre l'alcool et le date rape est d'ailleurs étayée par la chronologie. Des recherches menées dans le Massachusetts à douze ans d'intervalle, en 1977 puis en 1989, confirment ce que chacun pressent : l'abus d'alcool (que mesure l'ivresse répétée au moins trois fois dans le mois) ne cesse d'empirer dans la population étudiante. Et les cas extrêmes, entraînant le coma, ou la mort, ne sont pas rares. C'est vrai des hommes : l'abus concerne aujourd'hui $41 \%$ d'entre eux, contre $25 \%$ hier. Et c'est plus vrai encore des femmes : de $14 \%$, on passe à $37 \%^{31}$. Malgré l'accélération du phénomène, durant les années quatre-vingt, celles-ci ont donc presque rattrapé ceux-là - du moins en ce domaine. On le constate, la chronologie du date rape est parallèle à cette évolution, l'aggravation des abus d'alcool, et sans doute en même temps de drogue, accompagnant peut-être une recrudescence d'abus sexuels.

41 L'alcool est d'ailleurs un argument utilisé par les conservateurs, et plus encore par les post-féministes : elles l'ont bien cherché, suggèrent les premiers ; elles n'ont qu'à faire attention, ajoutent les secondes. D'un côté : pourquoi tenir les hommes responsables ? et de l'autre : pourquoi les femmes ne se montreraient-elles pas responsables? Bref, les femmes ne se font pas enivrer; elles se laissent enivrer, ou plutôt, elles s'enivrent. En réponse, le féminisme du date rape tient deux langages, moins contradictoires que complémentaires. Aux femmes, on prêche la prudence : le refus n'est possible qu'avec la sobriété. Aux hommes, on prêche la vigilance : le consentement est impossible dans l'ivresse. C'est d'ailleurs la logique, toute pratique, de cette double stratégie de lutte contre le date rape qui explique l'hésitation entre les deux modèles féministes, libéral et culturel. D'une part, on s'adresse à l'homme: "non c'est non", selon une logique libérale. D'autre part, c'est à la femme qu'on répond: pour l'aider, il faut toujours croire la victime. Cette règle d'or exige de se placer, comme le veut le féminisme culturel, du point de vue de la femme: c'est donc son intention qui guide l'interprétation. Chacune des deux démarches a fait l'objet de critiques farouches, sans qu'on en perçoive d'ordinaire l'articulation: on bascule en fait du registre juridique, avec la précaution, au registre psychologique de l'encouragement. C'est que les deux logiques se situent à deux moments chronologiques distincts: avant, et après. La première est préventive, la seconde thérapeutique. On comprend ainsi l'oscillation du féminisme du date rape, entre la logique libérale a priori et la logique culturelle $a$ posteriori.

On comprend aussi l'intérêt polémique des conservateurs et des post-féministes à réduire cette ambiguïté, pour ne voir dans le féminisme que sa variante culturelle, et peindre aux couleurs du radicalisme même la modérée Susan Estrich (également connue pour avoir animé en 1988 la campagne du démocrate Michael Dukakis, candidat malheureux à l'élection présidentielle). Il est vrai que la logique de l'invention du date rape se prête à cette lecture : la victime ne peut, ni n'ose appeler l'agression par son nom. Faute de pouvoir nommer leur expérience, les femmes sont condamnées à la fausse conscience. La perspective libérale s'en trouve affaiblie d'autant. Et l'attaque antiféministe s'en trouve renforcée d'autant: pour Norman Podhoretz, «ni les 
“violeurs" ni les "victimes" ne s'accordent avec les "spécialistes" ». Qu'est-ce qu'un viol qui n'existerait que dans sa fabrication féministe? La statistique la plus troublante sans doute dans les enquêtes de Ms. montre que « $42 \%$ des femmes qui ont été violées déclarent avoir ensuite repris des relations sexuelles avec leur agresseur ${ }^{32} »$.

Pour Robin Warshaw, même après coup, au moment d'interpréter leur expérience, les victimes ne peuvent ni n'osent penser ce qu'elles pensent, non plus que vouloir ce qu'elles veulent. Pour les sceptiques en revanche, quelle plus belle preuve de l'absurdité du date rape ? Seul le féminisme libéral reste entièrement démuni face à ces chiffres, pour le plus grand bénéfice de la polémique antiféministe. Sans prêter attention à celles qui, comme Susan Estrich, veulent faire du viol une affaire de violence, et non de sexualité, conservateurs et post-féministes identifient le féminisme du date rape à celles qui, comme Catharine MacKinnon, refusent de distinguer violence et sexualité. Il n'y aurait que deux camps : c'est selon Neil Gilbert « la différence entre un point de vue selon lequel les relations entre hommes et femmes sont normalement plaisantes pour la plupart des gens, et le point de vue selon lequel elles sont, de manière inhérente, dangereusement antagonistes ». Autant dire, pour reprendre un thème classique depuis deux siècles au moins, que l'érotisme (hétérosexuel) serait incompatible avec le féminisme.

\section{Quand « oui », c'est « oui » : un féminisme radical ?}

Avec Antioch, la polémique dirigée contre le date rape trouve sa cible de prédilection. Ce petit college de l'Ohio serait la caricature parfaite du « sexuellement correct ». La presse et la télévision s'emparent en effet durant l'été 1993, lors d'un creux médiatique, d'un règlement mis en place à la demande des étudiants, un an plus tôt, sur ce campus "progressiste». Il s'agit d'un véritable code érotique, qui ne se contente pas de proscrire, mais s'enhardit à prescrire les comportements. Le principe est simple : le consentement sexuel doit être explicite. Ainsi, qui ne dit mot ne consent pas - « double entendre" (comme on dit en anglais) et sous-entendu ne suffisent plus. Les conséquences sont plus complexes, en tout cas dans la pratique : le consentement doit être explicité à chaque étape $d u$ progrès amoureux (le baiser ne promet pas nécessairement une caresse, et la caresse n'entraîne pas inévitablement au lit) et, à chaque fois, d'un date à l'autre : l'acquiescement d'un soir n'engage pas au-delà. Bref, le consentement n'est jamais acquis d'avance ; et seule la parole explicite peut le garantir.

Cette règle du jeu nouvelle ne s'impose pas naturellement. Non pas, bien sûr, qu'une police du campus se charge de surveiller la conformité des comportements érotiques au règlement (nul d'ailleurs n'a encore été sanctionné). C'est plutôt qu'il faut enseigner le code amoureux aux nouveaux étudiants. Avec ces ateliers de rentrée universitaire, l'occasion est trop belle et, dans tous les États-Unis, les médias orchestrent un éclat de rire national. La quasi-unanimité dans la dérision est d'autant plus remarquable qu'en matière de violence sexuelle, le consensus se fait depuis le début des années quatrevingt aussi rare que l'humour ${ }^{33}$. La dénonciation conservatrice ou post-féministe était certes attendue: tous voient dans ce code l'expression caricaturale de la nouvelle orthodoxie féministe. Même l'hostilité libérale n'est pas faite pour surprendre: en ce domaine comme en d'autres, on préfère le laisser-faire à la régulation des mœurs. Pour tous les adversaires du code, l'amour est un fait de nature, ou une réalité individuelle, mais jamais une construction sociale : aussi échappe-t-il au langage. Il est toutefois plus 
remarquable que, si l'attaque ne rencontre (presque) aucune résistance, c'est que les féministes restent (presque) toutes silencieuses. Comment expliquer ce mutisme?

À Antioch, « oui », c'est « oui »- ou plus précisément : « oui » (et seulement oui), c'est (et c'est seulement) « oui ». C'est une des logiques virtuelles du féminisme du date rape qui trouve ici son expression achevée. Il est clair que la transparence du sujet de la sexualité rompt avec le sujet dominé du féminisme culturel : ici, le consentement n'est plus masqué, ni trompeur. Il sonne haut et fort. La femme non moins que l'homme parle (le règlement ne fait pas la différence entre les sexes), et elle sait ce qu'elle dit, ce qu'elle pense et ce qu'elle veut. Ce n'est pas pour autant la logique du féminisme libéral : la femme n'est plus seulement libre de refuser son consentement, mais aussi de le donner, de lui donner voix. Antioch renverse la liberté négative du féminisme libéral en une liberté positive. En effet, le féminisme libéral, non moins que culturel, est défini par rapport aux abus de la sexualité. Pour le premier, du désir il n'y a jamais rien à dire : il est privé. Pour le second, son désir échappe toujours à la femme: elle est dominée. Dans un cas comme dans l'autre, l'érotique féminine se devine en creux, mais sans jamais être dessinée. Ce que le modèle d'Antioch suggère, c'est au contraire une sexualité définie pour elle-même, par la volonté et l'affirmation. Le désir féminin est supposé de même nature que la sexualité masculine. Et c'est bien parce que cette équivalence remet en cause l'image convenue d'une sexualité féminine au consentement toujours problématique qu'elle soulève un pareil tollé.

Plus encore que le féminisme libéral ou culturel, Antioch prétend donc redéfinir les règles du jeu amoureux. En esquissant sur le papier les contours d'une érotique dont le féminisme du date rape laissait la place vide, le code d'Antioch en offre peut-être la version radicale - occultée depuis les années quatre-vingt, on l'a vu, par la querelle des féminismes culturel et radical. Radical, ce programme l'est moins en proposant des solutions extrêmes (dans le doute, et devant la confusion, exiger un consentement explicite pourrait relever du sens commun) qu'en ouvrant à la politique tout le champ de l'érotique (et non pas seulement de la violence sexuelle). Refusant une fois de plus de s'embarrasser de ces distinctions, la polémique préfère voir dans Antioch l'expression exacerbée d'une même logique, déjà à l'œuvre dans le féminisme de Susan Estrich et de Catharine MacKinnon : tous les féminismes ne font qu'un. C'est le cas par exemple de Charles Krauthammer, qui n'y voit que «le code sexuellement correct le plus strict, et le plus hilarant, dans toute l'Université américaine. » Ne faudra-t-il pas bientôt, avant toute relation sexuelle, « un contrat devant notaire ${ }^{34}$ »?

\section{Le contrat érotique}

48 L'image $d u$ "contrat » érotique connaît une fortune étonnante, comme chez Allan Bloom déplorant le désenchantement d'Éros : « La raison abstraite au service d'hommes et de femmes radicalement libres ne peut placer à la base de l'amour que le contrat - le contrat social, le contrat de mariage, avec pour modèle le contrat d'affaires. » Et de dénoncer cette juridisation de l'amour : «Le légalisme prend la place du sentiment ${ }^{35}$. " C'est aussi l'argument de son ami et collègue à Chicago, l'historien français François Furet, qui dénonce cette idéologie du droit : «Il faudra bientôt que les deux partenaires amènent leurs avocats pour dresser l'acte officiel avant de coucher ensemble ${ }^{36}$.»

Le contrat social souligne que le code érotique ne relève ni de la pure détermination naturelle, ni de la simple invention individuelle. Et c'est à juste titre que François Furet 
trouve dans le féminisme le projet politique, proprement démocratique, «de faire de l'acte sexuel quelque chose comme un contrat conclu par des volontés libres qui y ont expressément consenti ». Il est vrai que le féminisme du date rape, dans toutes ses variantes, libérale, culturelle, et bien sûr radicale, prétend réformer la sexualité. L'image peut toutefois engendrer un malentendu : le féminisme d'Antioch propose un contrat, non pas juridique, mais érotique. À preuve, l'absence de témoins : tout se passe entre les partenaires. Aussi, légalement, le code nouveau ne change-t-il rien - sauf l'argumentaire qu'un accusé peut invoquer pour sa défense : plus question de plaider le malentendu. Plutôt qu'un contrat, c'est donc un règlement, qui impose une règle de conduite - un code de bonnes manières, qui dicte une étiquette. La différence n'est pas sans importance : en réalité, demander aux partenaires de parler, avant, c'est vouloir leur éviter de plaider, après. Les différends sexuels, avec leurs plaintes et leurs procès, existent déjà : le tumulte de la juridisation ne s'accommode que trop bien du silence sexuel. Le règlement d'Antioch, plutôt qu'un symptôme, est un remède à la dérive chicanière.

Ce premier malentendu, théorique, peut en cacher un autre, historique. La régulation sexuelle n'est pas un phénomène nouveau, singulièrement aux États-Unis. La séduction y a de longue date fait l'objet d'une codification stricte. Ce n'est pas ici le lieu de retracer l'histoire du date, avec ses négociations sexuelles qui toujours ont supposé une règle du jeu partagée. Notons simplement que l'idée d'un contrat érotique n'est pas une invention féministe: l'étiquette ancienne n'était pas moins contraignante, ni moins explicite, dans les années trente ou cinquante. Mais après les années soixante, sous l'influence croisée de la libération sexuelle et de l'émancipation féminine, chacun joue à un jeu dont la règle n'est plus clairement donnée d'avance. C'est dans cette incertitude et cette confusion que se développe, sinon une guerre des sexes, du moins une tension sexuelle généralisée. En réaction, Antioch, et plus généralement le féminisme du date rape, ne font que rencontrer une volonté sociale floue, mais répandue depuis les années quatre-vingt, de réorganiser la sexualité, bref, de créer une nouvelle règle du jeu. On voit la nature du second malentendu. L'invention, ou la réinvention des règles, est certes une opération politique. Mais c'est l'ensemble des courants politiques, avec principalement les conservateurs et les post-féministes d'un côté, les féministes libérales et culturelles de l'autre, sans oublier l'ébauche d'un radicalisme, qui va s'y essayer - chacun entreprenant, tant bien que mal, d'imposer la nouvelle règle du jeu. Il serait donc absurde de n'imputer la politisation qu'aux unes (ou aux autres, d'ailleurs): tous sont partie prenante dans une bataille dont la redéfinition du code érotique est l'enjeu.

\section{Perspectives}

51 Nous voici donc loin de l'hégémonie féministe qu'on se plaît parfois à imaginer comme principe de la culture américaine. C'est la mise en scène publique des différends sexuels qui fait la singularité américaine. La critique du culturalisme ne conduit donc nullement à renoncer à penser la spécificité des cultures; il s'agit simplement de l'appréhender autrement, à la fois historiquement, pour cerner la singularité d'un moment, et politiquement, pour en préciser les enjeux. Le travail exposé ici s'inscrit en effet dans une recherche plus vaste, au croisement de deux projets. Le premier porte sur l'histoire de cette politisation, avec les différends sexuels multiples qui font et 
défont la société américaine contemporaine, de la question de la violence sexuelle aux controverses sur l'avortement et l'homosexualité. L'émergence de ces différends définit aujourd'hui dans la culture américaine un langage polémique commun, qui articule la sexualité et le genre. En retour, c'est dans ce langage que s'expriment des tensions sociales de tous ordres, d'où son importance, qui déborde largement du cadre des affaires exclusivement sexuelles.

Le second projet porte sur l'histoire de la culture érotique aux États-Unis au cours du $\mathrm{xx}^{\mathrm{e}}$ siècle, du rendez-vous amoureux à la demande en mariage. Les différends sexuels aujourd'hui portés sur la place publique ne se comprennent en effet qu'à la lumière d'une politique sexuelle privée, qui se joue dans les interactions érotiques quotidiennes. Le consentement amoureux, on l'a vu, est l'objet d'une politisation : la négociation amoureuse est plus que jamais, au lendemain d'une double revendication d'émancipation des femmes et de libération sexuelle, une relation proprement politique. L'analyse de l'intimité sexuelle est d'autant plus nécessaire à la compréhension des différends publics qu'elle révèle un point aveugle de la réflexion contemporaine aux États-Unis : paradoxalement, l'invention du date rape coïncide avec la disparition du date en tant qu'objet de recherche, au tournant des années quatrevingt. Tout se passe comme si, la règle du jeu échappant désormais au regard (sociologique non moins que social), seuls restaient aujourd'hui visibles les dérèglements de l'échange amoureux. C'est donc précisément au moment où l'anthropologie et la sociologie se désintéressent des codes amoureux que la psychologie et le droit se consacrent à ses dysfonctionnements, l'attention passant désormais de la culture à l'individu. Cette translation disciplinaire, qui accompagne un déplacement culturel, reflète sans doute l'opacité nouvelle de la relation amoureuse aux États-Unis ; elle ne contribue pas à l'éclairer. Tout comme le savoir, l'ignorance devient une affaire politique.

La différence transatlantique n'est donc culturelle que pour autant qu'elle est politique. De fait, les enquêtes sur la violence sexuelle tendraient à rapprocher plutôt qu'à opposer les deux cultures sexuelles. On découvre en effet en France, même si l'on n'y prête guère d'attention, une importance comparable de ces dérives - à la fois par son ampleur ( $7 \%$ des femmes de 20 à 34 ans se déclarent victimes de viol) et dans sa nature (dans un cas sur deux, le violeur est une personne connue mais étrangère à la famille). Sommes-nous si loin du date rape ? Pour Michel Bozon, « les rapports sexuels contraints se produisent bien souvent dans des contextes relationnels ordinaires où la contrainte apparaît comme une forme socialement tolérée de la domination masculine et une forme extrême de l'infériorisation sociale des jeunes femmes ${ }^{37}$ ». Ce qui distingue ici la France, c'est donc moins l'harmonie que l'occultation des tensions. C'est bien pourquoi le modèle américain fait l'objet d'un rejet si virulent en France : introduire avec les féministes la question du genre dans la sexualité, ce serait faire entrer le loup des relations de pouvoir dans la bergerie de la séduction hétérosexuelle. La polémique américaine fait aussi ressortir l'étrange absence de politisation de la violence sexuelle en France. Voilà qui suggère un programme de recherches sur la France explorant les conditions sociales, politiques et scientifiques d'une non-politisation, lequel pourrait dissiper en retour les facilités d'un exotisme français, vu des États-Unis. 


\section{NOTES}

1. M. Ozouf, Les mots des femmes. Essai sur la singularité française, Paris, Fayard, 1995, p. 388-389.

2. J.-C. Passeron, Le raisonnement sociologique. L'espace non-poppérien du raisonnement naturel, Paris, Nathan, 1991, p. 27. Les travaux dont on expose ici un pan ont trouvé leur première formulation, autour de la notion de "fait social total ", dans l'étude d'une autre polémique sexuelle, proposée «à chaud»: " Pouvoirs sexuels. Le juge Thomas, la Cour suprême et la société américaine ", Esprit, décembre 1991, p. 102-130, en particulier p. 129-130.

3. Elle fait l'objet d'un travail en cours. On trouvera l'histoire de cette érotique, entre le date et le companionate marriage, des années vingt aux années soixante, ébauchée dans mon article : «Un échange inégal. Sexualité et rites amoureux aux États-Unis », Critique, LIII, 596-597, 1997, p. 48-65.

4. Voir E. Kanin, «Male Aggression in Dating-Courting Relations", American Journal of Sociology, LXIII, 1957, p.197-204; C. Kirkpatrick et E. Kanin, «Male Sex Aggression on a University Campus ", American Sociological Review, XXII, 1957, p. 52-58.

5. Voir par exemple S. Griffin, «Rape : The All-American Crime», Ramparts, 10, 1971, p. 26-35, D. E. H. Russell, The Politics of Rape. The Victim's Perspective, New York, Stein et Day, 1975, et S. Brownmiller, Le viol, Paris, Stock, 1976 (éd. originale, New York, Simon et Schuster, 1975). Le mot date rape apparait ici, et sa réalité, mais seulement incidemment : voir l'édition de poche, New York, Bantam, 1990, p. 284 (le mot), 393-394 (les exemples).

6. A. G. Johnson, «On the Prevalence of Rape in the United States", Signs, Journal of Women in Culture and Society, VI, 1980, p. 136-146, citation p. 146 ; D. Russell et N. Howell, « The Prevalence of Rape in the United States Revisited ", ibid., VIII, 1983, p. 688-695, citation reprise p. 688 (et l'ouvrage de D. Russell, Sexual Exploitation. Rape, Child Sexual Abuse, and Workplace Harassment, Beverly Hills, Sage, 1984). Voir aussi la critique de Johnson par A. E. Gollin, «Comment on Johnson's "On the Prevalence of Rape in the United States" », ibid., VI, 1980, p. 346-349.

7. M. P. Koss et C. J. Oros, "Sexual Experiences Survey. A Research Instrument Investigating Sexual Aggression and Victimization», Journal of Consulting and Clinical Psychology, L, 1982, p. 455-457 ; M. P. Koss, C. A. Gidycz, N. Wisniewski, « The Scope of Rape. Incidence and Prevalence of Sexual Aggression and Victimization in a National Sample of Higher Education Students ", Journal of Consulting and Clinical Psychology, LV, 1987, p. 162-170.

8. Dans l'enquête de Koss, parmi les femmes «objectivement » violées, $27 \%$ nomment «viol » leur expérience, $16 \%$ y voient un crime sans l'appeler ainsi, $46 \%$ parlent d'un grave problème de communication et $11 \%$ ont le sentiment qu'aucun crime n'a été commis. D'autres enquêtes confirment ces écarts de perception. Ces chiffres deviennent un enjeu polémique: pour Neil Gilbert, « 73 \% parmi les femmes que l'enquête définit comme violées [...] ne se perçoivent pas comme des victimes" (p.60) ; pour Robin Warshaw, à partir des mêmes données, «seulement $11 \%$ déclaraient ne pas se sentir victimisées" (Avant-Propos, 1994, p. XXV) (références infra, notes 9 et 13).

9. R. Warshaw, I Never Called It Rape [1988], New York, Harper, 1994.

10. Time (New York), 23 mars 1987, p. 77 : «When the Date Turns into Rape », de J. Lee, et 13 juin 1991, p. 48-55: «When Is It Rape? », article de N. Gibbs.

11. Newsweek (New York), 25 octobre 1993, p. 52-64 : «Sexual Correctness : Has It Gone Too Far?» de S. Crichton.

12. Comme chacune des querelles a son dictionnaire satirique, chacune a ses anthologies, ici: Debating Sexual Correctness (A. M. Stan, ed., New York, Delta, 1995).

13. N. Gilbert, « The Phantom Epidemic of Sexual Assault », The Public Interest, 103, 1991, p. 54-65 ;

N. Podhoretz, « Rape in Feminist Eyes », Commentary, XCII, 4,1991, p. 29-35. 
14. C. Paglia, "Rape: a Bigger Danger than Feminists Know", "Op-Ed», New York Newsday, 27 janvier 1991, repris (sous un autre titre) dans Sex, Art and American Culture, New York, Vintage, 1992. K. Roiphe, «Date Rape Hysteria », « Op-Ed», The New York Times, 20 novembre 1991; la couverture du magazine du New York Times: «Rape Hype Betrays Feminism », 13 juin 1993, et le livre, The Morning After. Sex, Fear, and Feminism on Campus, New York, Little, Brown and Co., 1993.

15. C. Paglia, Sexual Personae. Art and Decadence from Nefertiti to Emily Dickinson [1990], New York, Vintage, 1991, p. 24. Les autres citations sont extraites de l'autre volume déjà mentionné.

16. " Affirmez-vous ", " Gardez le contrôle », "Comptez sur vous-même » : le paradoxe, c'est que ces prescriptions sont au centre du manuel de lutte contre le date rape de R. Warshaw, op. cit., p. 154-156. La véritable différence, c'est l'appel à la prudence que rejette explicitement Roiphe, op. cit., p. 83 : « Restez sobre », continue en effet la liste. La critique conservatrice, si elle force le trait, est donc plus fidèle à la logique du féminisme du date rape que la critique post-féministe.

17. Notons que c'est encore Robin Warshaw qui recommande aux femmes d'apprendre les techniques d'auto-défense, tout en reconnaissant qu'il faut parfois capituler devant la force : «Céder n'est pas consentir ». Prescription ultime : « Restez en vie » (op. cit., p. 160).

18. C. Hoff Sommers, op. cit., p. 219-221.

19. "The "Date Rape" Issue : Feminist Hysteria, Anti-Sex Witchhunt ", Women and Revolution, 43, hiver 1993-printemps 1994, p. 8-15.

20. K. Roiphe, The Morning After, op. cit., p. 76-79.

21. N. Wolf, The Beauty Myth. How Images of Women are Used against Women [1991], New York, Anchor, 1992, citation p. 167, et Fire With Fire. The New Female Power, New York, Random House, 1993, voir p. 135-136, 191-197 ; S. Faludi, Backlash. The Undeclared War against American Women [1991], New York, Anchor, 1992.

22. Quelques rares études s'intéressent pourtant à la question des victimes masculines de la violence sexuelle : C. Struckman-Johnson, «Forced Sex on Dates : It Happens to Men, too ", The Journal of Sex Research, 24, 1988, p. 234-241, et à la violence sexuelle perpétrée par des femmes : E. H. Thompson Jr, "The Maleness of Violence in Dating Relationships: an Appraisal of Stereotypes ", Sex Roles, 24 (5-6), 1991, p. 261-276. En fait, le viol des hommes semble être dans la très grande majorité des cas un viol par des hommes (en particulier en prison).

23. G. David Johnson, G. J. Palileo et N. B. Gray, «"Date Rape" on a Southern Campus : Reports from 1991 ", Sociology and Social Research, 76 (2), 1992, p. 37-44. Les chiffres : $35 \%$ jamais, $17 \%$ souvent, $17 \%$ toujours, sur un échantillon de 666 étudiantes (et le reste, rarement ou parfois).

24. C. L. Muehlenhard et L. C. Hollabaugh, « Do Women Sometimes Say No When They Mean Yes? The Prevalence and Correlates of Women's Token Resistance to Sex », Journal of Personality and Social Psychology, 54 (5), 1988, p. 872-879 (« chances are that she means it »).

25. R. Warshaw, op. cit., p. 164. Citée par N. Podhoretz, op. cit., p. 34.

26. Voir C. S. Vance, ed., Pleasure and Danger. Exploring Female Sexuality, New York, Routledge, 1984, qui relate cette querelle des féminismes.

27. A. Dworkin, Intercourse, New York, The Free Press, 1987, p.64-67, et le chapitre 7, «Occupation / Collaboration».

28. C. MacKinnon, "Rape: On Coercion and Consent", Toward a Feminist Theory of the State, Cambridge, Harvard University Press, 1989, p. 172-183, citations, passim.

29. Ibid., p. 183.

30. S. Estrich, Real Rape, Cambridge, Harvard University Press, 1987, p. 100-102.

31. M. Crystal Cage, «Probabilicy that Students Will Drink to Become Intoxicated Found to Rise ", The Chronicle of Higher Education (Washington), 10 juin 1992, à partir d'une enquête publiée dans le Journal of the American Medical Association.

32. R. Warshaw, op. cit., p. 63. 
33. Sur la logique de ce consensus, je me permets de renvoyer à mon texte, «Playing by the Antioch Rules ", The New York Times, 26 décembre 1993, repris dans Debating Sexual Correctness, op. cit., p. 97-100.

34. C. Krauthammer, «Defining Deviancy Up», The New Republic, 22 novembre 1993, p. 20-25 ; en français, «La déviance redéfinie à la hausse. Réponse à Daniel Patrick Moynihan », Le Débat, 81, septembre-octobre 1994, p. 167-176.

35. A. Bloom, «La chute d'Éros ", introduction à L'amour et l'amitié, Paris, de Fallois, 1996, p. 24. C'est Pierre Manent qui a traduit cet ouvrage posthume, Love and Friendship, New York, Simon and Schuster, 1993. L'introduction, critique politique du présent, avait été reprise en bonnes feuilles dans le magazine du New York Times, le 23 mai 1993 ("The Death of Eros », citation p. 84), la faisant aussitôt entrer dans le débat public.

36. F. Furet, «L'utopie démocratique à l'américaine », Le Débat, 69, mars-avril 1992, p. 86.

37. M. Bozon, «La violence sexuelle ", in A. Spira et N. Bajos, eds, Les comportements sexuels des Français, Paris, La Documentation Française, 1992, p. 218.

\section{RÉSUMÉS}

Pour appréhender une culture, on peut partir, non des représentations partagées, mais des polémiques qui la déchirent. Ainsi du date rape aux États-Unis, invention du féminisme universitaire et médiatique des années 1980 : en posant la question de la violence au cœur des rapports amoureux, le féminisme impose moins une orthodoxie qu'il ne propose une interprétation, doublement contestée durant les années quatre-vingt-dix par les intellectuels conservateurs et les essayistes "post-féministes ». Déployer les rhétoriques et les idéologies, à rebours des amalgames de la polémique, c'est parcourir le spectre des représentations de la sexualité féminine, de l'érotique conservatrice aux féminismes culturel, libéral, et même radical. À la différence de la France, il s'agit bien aujourd'hui aux États-Unis d'une politisation de l'érotique, dont l'enjeu est, non pas la négation par le contrat juridique, mais la réinvention des règles sociales du jeu amoureux.

To approach a culture, one point of departure can be not shared representations, but polemics which divide it. Such as for example, date rape in the United States, an invention of university feminism and the media in the 1980's: in placing the question of violence at the heart of love relationships, feminism rather than imposing an orthodoxy proposes an interpretation which is doubly contested during the 1990's by conservative intellectuals and post feminist essayists. The unfolding of the rhetorics and ideologies against the amalgams of the polemic, allows us to survey the spectre of representations of feminine sexuality, from conservative eroticism to cultural, liberal and even radical feminisms. Contrary to France, today in the United States it is a matter of politicizing of the erotic, in which the stake is not negation by juridical contract, but the reinvention of social rules of the love game. 


\section{AUTEUR}

\section{ÉRIC FASSIN}

Eric Fassin (École normale supérieure) étudie la société américaine contemporaine ; son travail, qu'éclairent à la fois la comparaison transadantique et sa critique, porte essentiellement sur les polémiques sexuelles, mais aussi raciales et médiatico-intellectuelles. Il vient de publier : «Discours sur l'inégalité des races. The Bell Curve : polémique savante, rhétorique raciale et politique publique ", in Hérodote (Paris), $2^{\mathrm{e}}$ trimestre 1997, 85, pp. 34-61. 